\title{
Attitudes and Perceptions of Tobacco-Related Products in College Students
}

Yen H. Dang, PharmD, CTTS-M

University of Maryland Eastern Shore, School of Pharmacy and Health Professions, Department of Pharmacy Practice

\begin{abstract}
Background - Despite the highly publicized health consequences, some college students do not perceive tobacco consumption as harmful. Historically-Black College and Universities (HBCUs) have the lowest rates of tobacco-free policies compared to other colleges, universities, and minority-serving institutions, making their students at higher risk for tobacco abuse. A campus Alcohol, Tobacco, and Other Drug Prevention Committee (ATDP) was formed and led by a pharmacist to develop all tobacco cessation policies at the HBCU.

Objectives - (1) To determine the knowledge and attitudes of cigarettes, cigars, smokeless tobacco, electronic cigarettes, and hookah among college students in a rural area with high tobacco usage; (2) To assess perceptions on the effectiveness of smoking cessation resources on the college campus led by the ATDP committee.

Methods - A cross-sectional study was conducted on 99 students between 18 - 26 years attending a HBCU in Maryland. The online survey was disseminated to assess student's health behaviors and attitudes towards tobacco products and their successfulness in abstinence using campus resources with the Health Belief Model.

Results - Participants had more perceived harms with smoking tobacco (cigarettes and cigars) and smokeless tobacco, and greater perceived benefits with using electronic cigarettes and hookah $(P<0.001)$. Most students had limited knowledge of the four tobacco categories (5.8 \pm 2.6 on a 10-point Likert scale). Self-efficacy to quit was $4.2 \pm 1.7$ on a 10-point Likert scale despite the current resources at the $\mathrm{HBCU}$.

Conclusion - Students had a perceived benefits sequential rank order with hookah, e-cigarettes, smokeless tobacco, followed by smoking tobacco. Campuses should investigate barriers for abstinence, raise awareness about the dangers of tobacco, and create programs that enhance self-efficacy when quitting.

Innovation and Practice Implication - This is the first study of its kind that compares all major tobacco products head-to-head in a rural and underrepresented population. Additionally, the development of a campus-wide tobacco policy was novel as it was pharmacist-led. The results show this population has limited knowledge of tobacco products with more perceived benefits among newer nicotine delivery systems. Targeted education and public health programs should be implemented to prevent this susceptible group from initiating and continuing tobacco products.
\end{abstract}

Keywords: cigarettes; cigars; hookah; electronic cigarettes; smokeless tobacco; college students

\section{Introduction}

According to the Centers for Disease Control and Prevention, approximately half a million people die each year due to a tobacco-related complication, making it the most preventable cause of death in the United States. ${ }^{1}$ Cigarettes and cigars contains more than 60 known carcinogens and thousands of other harmful substances. ${ }^{2}$ Cardiovascular disease, respiratory disease, cancer, and negative reproductive effects are among some of the leading consequences of tobacco usage. ${ }^{1,2}$ Additionally, while smokeless tobacco is less commonly used than cigarettes, it is also associated with adverse events including oral cancer, gum disease, and tooth loss. ${ }^{1,2}$ Inhaling or ingesting tobacco results in three-times higher mortality rates compared to the general population which results in billions of dollars in healthcare losses every year. ${ }^{1}$

Corresponding author: Yen H. Dang, PharmD, CTTS-M

Associate Professor of Pharmacy Practice

University of Maryland Eastern Shore

School of Pharmacy and Health Professions

One College Backbone Road, 210 Somerset Hall

Princess Anne, MD 21853

Phone: 410-651-8169; Fax: 410-651-8394

E-mail: ydang@umes.edu
Newer methods for introducing nicotine in the body have been developed with increasing popularity in youth. Electronic cigarettes (e-cigarettes) are battery-powered devices which aerolize nicotine, propylene glycol, and other flavorings through vaporized liquid. Hookahs are water pipes filled with tobacco and other flavorings. These products have been marketed as less harmful than their counterparts, contain numerous appealing flavor options, possess fewer regulations, and have been widely accepted in the social scene. ${ }^{3}$ Despite conflicting reports, studies show that there are some differences between these products than traditional cigarettes and that the effects of these products are largely still unknown. ${ }^{3}$

One of the latest public health initiatives is to limit tobacco consumption in younger adults, especially those on college campuses. Approximately $90 \%$ of the population use their first tobacco product by age eighteen, and $98 \%$ of adults begin using a tobacco product by age $26 .{ }^{4}$ Targeting college students becomes a critical population for tobacco education as this group is most susceptible for tobacco initiation. Despite the highly publicized health consequences, some college students do not perceive tobacco consumption having negative health consequences. In a study by Kong et al. ${ }^{5}, 36.6 \%$ of students perceived harm among all tobacco products, $48.2 \%$ perceived 
harm in newer tobacco products, and $8.6 \%$ of participants never heard of tobacco products at all. Those who were unaware of product harms were more likely to be younger, have a lower education level, and were minorities. ${ }^{5}$ In an attempt to mitigate the damages associated with tobacco consumption, most colleges have enacted to ban tobacco consumption around campus. The American Nonsmokers' Rights Foundation (ANRF) states that there are currently 2,487 accredited universities nationwide that have established policies for smoke-free campuses. ${ }^{6,7}$ However, Historically Black College and Universities (HBCUs) have the lowest rates of tobacco-free policies compared to other colleges, universities, and minority-serving institutions. Among the $58 \mathrm{HBCUs}$ with smoke-free policies, 42 (72.4\%) are tobacco-free, 37 (63.8\%) specifically ban e-cigarette use, and $28(48.3 \%)$ specifically ban hookah smoking. ${ }^{6,7}$ Many students struggle to refrain from using tobacco and most campuses have difficulty enforcing the tobacco-free policy due to failures of raising awareness for the policy, a lack of policy enforcement, and limited resources for abstinence. $^{8}$

This cross-sectional study was conducted at a HBCU in a county that had the highest rate of tobacco consumption in the State of Maryland. An estimated $22.0 \%$ of the youth in the area reported using some form of tobacco. ${ }^{9,10}$ The incidence of lung, bronchus, and tracheal cancer were ranked as the number one risk of death in the county. ${ }^{9,10}$ Youth were especially vulnerable in this area with $12.4 \%$ using cigarettes, $13 \%$ using cigars, $10.3 \%$ using smokeless tobacco, and $19.6 \%$ using e-cigarettes. ${ }^{11}$ These rates were at least $5 \%$ higher than the state average. ${ }^{11}$ Additionally, minorities reporting tobacco usage in this area had increased to $23.5 \%$, compared to only $14.6 \%$ of minorities in State of Maryland. ${ }^{10,11}$

While the HBCU prohibited tobacco usage on university property, there were designated zones around the perimeter of the campus where tobacco was allowed. An Alcohol, Tobacco, and Other Drug Prevention Committee (ATDP) was created and chaired by a pharmacist with certifications in tobacco dependence. A public health faculty, rehabilitation faculty, law enforcement officer, counselor, building manager, and three full-time students were also assigned to the initiative. The committee was responsible for the development and enforcement of these tobacco-free policies, including fines for violators. The policy was available in printed and electronic formats in the Student Handbook. Additionally, the committee oversaw education and awareness campaigns on tobacco usage including pamphlets, signage, and workshops. The committee provided smoking cessation resources (e.g. counseling) and made smoking cessation materials available. The committee met monthly to review regulations and evaluate practices.

The Health Belief Model was used as the framework to develop survey questions and understand students' behavior towards tobacco products in this study (Appendix I). The theory has six main constructs that influence people's decisions to take actions to prevent, screen for, and control illness. ${ }^{12}$ Perceived susceptibility refers to the likelihood of getting the disease. Perceived severity is the seriousness of contracting illness. Perceived benefits are the efficacy of action to reduce the risk of impact. Perceived barriers refers to belief about the tangible and psychiatric costs of advised action. Cues to action are strategies to activate readiness. Self-efficacy is the confidence in one's ability to take action. The Health Belief Model theorizes that a person's belief in a threat of disease combined with a belief in the effectiveness of the health behavior will predict the likelihood of a person adopting the change in behavior. ${ }^{12}$

The objective of this study was to determine the knowledge, perceptions, and attitudes of different tobacco products among college students attending a $\mathrm{HBCU}$ in an underserved community with the highest prevalence of tobacco usage in the state. This was the first study of its kind that compared the perceptions and attitudes of five different tobacco products head-to-head in a rural and underrepresented population. Additionally, this study assessed student's perceptions of the effectiveness of campus smoking cessation policies that was spearheaded by a pharmacist.

We hypothesized that college students would be more likely to use novel tobacco delivery devices such as e-cigarettes and hookah. We believed that these products would have less associated harms to target organs and disease states compared to conventional tobacco products such as cigarettes, cigars, and smokeless tobacco. We believed that the younger generation would understand the perceived benefits of abstinence and were offered cues to action by the ATDP committee. However, we predicted that they would retain an overall low self-efficacy level for tobacco cessation due to their perceived barriers.

\section{Methods}

Undergraduate and graduate students at a HBCU were surveyed with a 21-item web-based questionnaire that was distributed via email listserve to all students in the university, regardless of prior tobacco use. Participants were enrolled fulltime at the college and between 18 and 26 years old as initiation of tobacco is unlikely to occur after the age of $26 .{ }^{4}$ Survey results were anonymously collected. After completion of the survey, participants were directed to information on the Centers for Disease Control and Prevention's website to learn more about the adverse effects of tobacco use. Definitions of tobacco product terminology used in this study is provided in Appendix II. ${ }^{15}$ The four categories that were compared in this study included smoking tobacco (cigarettes and cigars), smokeless tobacco, e-cigarettes, and hookah. Cigarettes and cigars were grouped together under the "smoking tobacco" category due to their similar nicotine delivery system, ingredients, and side effect profiles. The study was granted approval through the investigational review board and expedited review was granted. 
Survey questions were based on the Health Belief Model to assess students' health behaviors. Perceived susceptibility, severity, and benefits of the four tobacco-related categories were assessed by asking participants to compare and rank the four tobacco-related categories in relation to each other. Products were ranked in sequential order by their perceived likelihood to cause harm or benefit to the pulmonary system, cardiovascular system, pregnancy, potential to cause cancer, addictive potential, and production of second-hand smoke. Scoring was assigned to each rank, with the products perceived as the least likely to cause harm and most benefit scoring one point, increasing to a maximum of four points for products ranked as causing the most harm and least benefit (Appendix III).

Participants were asked to provide their perceived barriers for quitting the tobacco product, if applicable, through short answers in both tangible and psychological terms. Additionally, participants were asked to develop strategies for cues for action that could be initiated on college campuses to help them remain abstinent. Students rated their knowledge of tobacco products on a 10-point Likert scale of 1 (lowest knowledge level) to 10 (highest knowledge level) to measure their cues of action. Finally, students were asked to rank their self-efficacy to terminate tobacco products on a 10-point Likert scale ( 1 = least to 10 = most self-efficacy) with the current policies and resources at the $\mathrm{HBCU}$.

All analyses were performed using SAS version 9.2. Descriptive statistics were used, and chi-square analysis was performed for categorical data. P-values were significant at an alpha level of less than 0.05

\section{Results}

Of the 980 students who received the survey, 99 students participated in the study with a $10.1 \%$ response rate. The majority of participants were female (64.6\%) and AfricanAmerican (66.7\%). The survey took on average 15 minutes to complete. The demographics of the participants are shown in Table 1. The study population primarily consisted of undergraduate students $(90.9 \%)$ who mostly were in the technology major. Half of all respondents stated that they used one of the five tobacco products at least once in their lifetime. In the subgroup that reported using a tobacco-related product periodically, hookah was the most popular (32.3\%). Hookah was reported to be used a couple of times a year for a total duration of less than five years. This was followed by cigarettes (26.2\%), e-cigarettes (15.1\%), smokeless tobacco $(3.0 \%)$, and cigars $(2.0 \%)$. Many students reported using more than one tobacco product in their lifetime.

The results are shown in Figure $\mathbf{1}$ and there were statistically significant differences in responses for perceived benefits and harms among all the four tobacco groups $(P<0.001)$. Smoking tobacco was rated as the highest likelihood of toxicity on the pulmonary system, cardiovascular system, pregnancy, cancer, addiction, and for second-hand smoke. Additionally, students predicted that smoking tobacco was the most expensive type of tobacco-related product and the most commonly used by college students. Smokeless tobacco was rated as the least detrimental to others who were exposed to it (second-hand smoke) and was the least expensive product. Hookah was ranked as having the lowest potential for harm during pregnancy, potential for causing cancer, and addiction risk. Students ranked electronic cigarettes as having the most benefit for the pulmonary and cardiovascular system. Participants ranked their overall knowledge of tobacco-related products to be $5.8 \pm 2.6$ on a 10 -point Likert scale.

Of the $52.5 \%$ of participants that reported using tobacco products, the majority $(37.3 \%)$ reported that they did not attempt to quit. Top reasons in the 14 students that reported quit attempts included personal health benefits (36.5\%), financial reasons (17.3\%), and social pressures (15.3\%). Of the respondents that used tobacco products in the past, ninety-two percent of respondents had never tried any tobacco cessation product during their tobacco use history. Perceived barriers to cessation include the loss of a way to handle stress (76.9\%), withdrawal symptoms (7.7\%), and weight gain (5.8\%). Participants reported that their ability to abstain from tobacco use would be maintained if fines or other citations were enforced for tobacco products on campus regularly (3.8\%), a stable social support system was created (7.7\%), educational sessions on the harms of tobacco products were made electronic (19.2\%), and smoking cessation aids were provided on campus free-of-charge (67.3\%). Despite these factors, students ranked their self-efficacy to quit as a $4.2 \pm 1.7$ on a 10 point Likert scale with the ATDP committee's current policies and resources.

Subgroup analyses performed showed that African Americans $(P=0.023)$, males $(P=0.042)$, those who have used tobacco products in the past $(\mathrm{P}=0.041)$, and participants who have made no quit attempts $(P=0.012)$ were more likely to have lower selfefficacy for quitting. Additionally, males $(P=0.028)$, those without a college degree $(P=0.034)$, and those who have smoked for 5 years of less $(P=0.028)$ had lower rates of tobacco knowledge. Type of educational major $(P=0.82)$, type of past tobacco product usage $(P=0.27)$, and tobacco product usage frequency $(P=0.38)$ were not associated with self-efficacy or tobacco knowledge rates.

\section{Discussion}

While government regulations and public health campaigns have lessened the usage of conventional cigarettes in the public domain by $33 \%$, the usage of alternative tobacco products has grown in the younger population. ${ }^{13}$ Increased availability, clever marketing, low cost, and perceptions of safety have spurred the rise of electronic cigarettes and hookah in young adults as alternatives to cigarettes, cigars, and smokeless tobacco. ${ }^{14}$ In this current study, the most commonly used tobacco product was hookah, used in $32.3 \%$ of the study 
population, which mirrors the prevalence rates in other studies, although the rates of cigar usage was lower. ${ }^{13,14}$ This is an interesting finding as cigars are heavily marketed to the African American population, although the rural location of this study may make successful marketing campaigns difficult. ${ }^{15}$ In our study, African American males who used tobacco products in the past were more likely to use newer tobacco delivery systems and have lower self-efficacy for abstinence. This confirms other findings where college users of alternative tobacco products were more likely to be younger, male, black, and concomitant cigarette users. ${ }^{16}$

The mixed results of perceived benefits and harms reported in this study reflect that there have been little head-to-head comparisons among the different tobacco products. Our study population perceived the sequential benefit rank order to be hookah (most benefit), e-cigarettes, smokeless tobacco, and smoking tobacco (least benefit). This is similar to other trials where alternative tobacco products were reported to be safer than conventional ones in young adults. ${ }^{17-20}$ Like other studies, this trial shows that harmful perceptions were correlated among participants of male gender, younger adults, and those with more education. ${ }^{17}$ However, while most people reported that e-cigarettes were safer than conventional cigarettes, many were concerned with the unfamiliar ingredients in the device, lack of product regulation, and addiction risk. ${ }^{21}$ This may be attributed to the Food and Drug Administration (FDA)'s lack of regulation for the manufacturing, distribution, and sale of hookah and e-cigarettes. ${ }^{22}$ This study was conducted when respiratory illnesses were associated with using vaping products. This prompted the FDA to restrict the production and sale of all flavored cartridge-based e-cigarettes to underage youth. 22,23 Yet, in our study, students were unaware of lung damage claims and perceived e-cigarettes to have the most benefit on the respiratory system. Moreover, the long-term health effects of these products are still unknown and widely debated. 22,23

There is limited knowledge of tobacco-related products, particularly those that are novel in design, among young adults that leads them to a false sense of security. In a study among US students by Wang et al., ${ }^{24}$ product knowledge and awareness were present in only $50.3 \%$ of students using ecigarettes and $41.2 \%$ using hookah. Blacks were less likely to have awareness of hookah products as a novel tobacco delivery device. ${ }^{24}$ Our study showed that hookah usage had the least perceived harms in our predominantly African-American sample, and this can be attributed to the majority of the population using hookah at baseline. Moreover, a focus group of adolescents and young adults by Wiseman et al. ${ }^{25}$ revealed that most did not know the components in novel tobacco products, although all respondents had negative views about the ingredients. All participants requested more information about the safety and toxicity profile of these products on the body. ${ }^{25}$ Similarly, in our study, hookah followed by e-cigarettes was perceived as having the least harms on most target organs compared to smoking tobacco, but participants reported an overall low understanding of all tobacco products. These results show the need for tobacco cessation interventions and education campaigns to reduce the usage of tobacco products among college students.

The ATDP committee created at the HBCU was unique as it was led by a pharmacist to address needs related to tobacco policy, compliance, enforcement, and cessation. The interdisciplinary nature of the task-force formed with students, staff, and faculty, was diverse enough to capture different stakeholders for tobacco cessation. The success of the committee's monthly meetings allowed interventions to be implemented in a timely manner. Pharmacy organizations and universities have advocated for the role of pharmacists in policy development for tobacco control. ${ }^{26}$ Pharmacists are well positioned to create public health policies to eliminate tobacco usage on college campuses. Many studies have shown the clinical and costeffectiveness of pharmacist-led interventions for tobacco cessation. ${ }^{27}$ The non-pharmacological and pharmacological interventions developed by pharmacists deliver sustainable health services and optimize patient care. ${ }^{27}$

Tobacco-free campus policies and those that include partial smoking restriction have been enforced with mixed results on college campuses. These polices have been paired with smoking cessation programs, especially those that offer complementary smoking cessation aids and education, to allow for more successful approaches. Difficulties of enacting comprehensive tobacco control programs include the lack of enforced policies and the variability of services. ${ }^{28,29}$ Colleges should promote the distribution of educational material in non-conventional means to younger students, including electronic pathways and social media, about tobacco harms and perceived barriers to abstinence. $^{30}$ This should be done in conjunction with treatment referrals to an affiliated health center or health department for smoking cessation pharmacotherapy. The programs should be targeted to novel tobacco agents, if possible. Finally, support groups with student mentors and family members should be incorporated in the treatment approach. ${ }^{30}$ College campuses should continue evaluating their programs routinely for the effectiveness of implementation.

This study was innovative in its approach to understand attitudes and perceptions of college students at a HBCU in an underserved area. Additionally, this study had a novel approach in which all tobacco products were analyzed for knowledge and compared against one another. The tobacco-free policies that the HBCU enforced were developed and reviewed by a pharmacy-led committee. Limitations included the crosssectional nature of the study that prevented making causal inferences on the findings. The response rate was low so the generalizability of the study could be affected. Additionally, many of the participants who used tobacco products did not try any smoking cessation aids, which implied that this population had more addictive potential to tobacco products compared to 
others. Moreover, less than half of the participants rated their literacy of tobacco products as adequate. The perceived harms and benefits may have been skewed with their limited knowledge as no information was provided in the survey about these products beforehand. Finally, the Health Belief Model does not consider habitual behaviors, environmental, or economic factors to accept a recommended action, and it has low predictive capability. ${ }^{12}$

\section{Conclusion}

Out of the four tobacco categories, hookah had the highest prevalence among college students, followed cigarettes, ecigarettes, smokeless tobacco, and cigars. While college students ranked smoking tobacco (cigarettes and cigars) and smokeless tobacco to have more perceived harms, hookah and e-cigarettes had greater perceived benefits on target organs. There remains limited knowledge of youth about tobacco products, particularly those that are novel in design. Campaigns on college campuses to raise awareness about the dangers of tobacco usage and programs that offer tobacco cessation management should be targeted to young students about novel tobacco products. Pharmacists are instrumental in the tobacco cessation process for policy development, evaluation, and enforcement. Finally, campuses should investigate barriers for abstinence among youth and create programs that enhance self-efficacy when quitting.

Acknowledgements: The author would like to thank Ms. Bianca Parker, University of Maryland Eastern Shore Rehabilitation Student, for her assistance in data collection. Additionally, I would like to thank Dr. Robert Freeman, Professor of Pharmacy Practice and Administration at the University of Maryland Eastern Shore, for his help in statistical analysis.

Financial Disclosure: This research did not receive any specific grant from funding agencies in the public, commercial, or notfor-profit sectors.

Conflicts of Interest: I declare no conflicts of interest or financial interests that the author has in any product or service discussed in the manuscript, including grants (pending or received), employment, gifts, stock holdings or options, honoraria, consultancies, expert testimony, patents and royalties.

Treatment of Human Subjects: Expedited IRB review/approval required and obtained

Dual Publication: The results/data/figures in this manuscript have not been published elsewhere nor are they under consideration in another journal.

\section{References}

1. Office on Smoking and Health, National Center for Chronic Disease Prevention and Health Promotion. Tobacco-Related Mortality. https://www.cdc.gov/tobacco/data_statistics/fact_sh eets/health_effects/tobacco_related_mortality/index .htm. Accessed September 8, 2020

2. U.S. Department of Health and Human Services. The Health Consequences of Smoking - 50 Years of Progress: A Report of the Surgeon General. Atlanta: U.S. Department of Health and Human Services, Centers for Disease Control and Prevention, National Center for Chronic Disease Prevention and Health Promotion, Office on Smoking and Health, 2014. Accessed September 8, 2020.

3. Gentzke AS, Creamer M, Cullen KA, et al. Vital Signs: Tobacco Product Use Among Middle and High School Students-United States, 2011-2018. Morbidity and Mortality Weekly Report 2019;68:157-164. doi: http://dx.doi.org/10.15585/mmwr.mm6806e1.

4. U.S. Department of Health and Human Services. The Health Consequences of Smoking - 50 Years of Progress: A Report of the Surgeon General. Atlanta: U.S. Department of Health and Human Services, Centers for Disease Control and Prevention, National Center for Chronic Disease Prevention and Health Promotion, Office on Smoking and Health, 2014. Accessed September 8, 2020.

5. Kong $\mathrm{G}$, Simon $\mathrm{P}$, Mayer ME, et al. Harm Perceptions of Alternative Tobacco Products among US Adolescents. Tob Regul Sci. 2019 May;5(3):242-252. doi: 10.18001/TRS.5.3.3.

6. Wang TW, Tynan MA, Hallett C, et al. Smoke-Free and Tobacco-Free Policies in Colleges and Universities United States and Territories, 2017. MMWR Morb Mortal Wkly Rep. 2018;67:686-689. doi: http://dx.doi.org/10.15585/mmwr.mm6724a4

7. American Nonsmokers' Rights Foundation. Smokefree and Tobacco-Free U.S. and Tribal Colleges and Universities. https://no-smoke.org/wpcontent/uploads/pdf/smokefreecollegesuniversities.p df . Accessed April 7, 2020.

8. Kong $\mathrm{G}$, Simon $\mathrm{P}$, Mayer $\mathrm{M}$. The carrot and the stick? Strategies to improve compliance with college campus tobacco policies. J Am Coll Health. 2017 FebMar;65(2):122-130. doi: 10.1080/07448481.2016.1262380. Epub 2016 Nov 21.

9. Maryland Comprehensive Cancer Control Plan. Tobacco-use prevention/cessation and lung cancer. Maryland Department of Health. http://phpa.dhmh.maryland.gov/cancer/cancerplan/ plan2011/Chapter5Tobacco.pdf. Accessed September $8,2020$. 
10. Chen JC, Mann DA, Hussein CA. Maryland chartbook of minority health and minority health disparities data with sections on gender-specific health and jurisdiction-specific health: third edition. Maryland Department of Health.

http://dhmh.maryland.gov/mhhd/SitePages/Health\% 20Equity\%20Data.aspx. Accessed September 8, 2020.

11. Maryland Department of Health. Cigarette Restitution Fund: Center for Tobacco Prevention and Control. Monitoring Changing Tobacco Use Behaviors: Maryland 2000 - 2016.

https://phpa.health.maryland.gov/ohpetup/Docume nts/2000\%20-

\%202016\%20Legislative\%20Report\%20Monitoring\%2 0Changing\%20Tobacco\%20Use\%20Behaviors.pdf. Accessed September 8, 2020.

12. Pose JE. Developing a new model for cross-cultural research: synthesizing the Health Belief Model and the Theory of Reasoned Action. ANS Adv Nurs Sci. 2001;23(4):1-15. PMID: 11393246.

13. Lauterstein D, Hoshino R, Gordon T, Watkins BX, Weitzman M, Zelikoff. The changing face of tobacco use among United States youth. Curr Drug Abuse Rev. 2014;7(1):29-43. PMID: 25323124.

14. Kasza KA, Ambrose BK, Conway KP, et al. TobaccoProduct Use by Adults and Youths in the United States in 2013 and 2014. N Engl J Med. 2017; 376(4): 342-353. doi: 10.1056/NEJMsa1607538. PMID: 28121512.

15. Smiley SL, Kintz N, Rodriguez YL, et al. Disparities in retail marketing for little cigars and cigarillos in Los Angeles, California. Addict Behav Rep. 2019; 9:110149. https://doi.org/10.1016/j.abrep.2018.100149.

16. Enofe N, Berg CJ, Nehl NJ. Alternative Tobacco Use among College Students: Who is at Highest Risk? Am J Health Behav. 2014; 38(2): 180-189. doi: 10.5993/AJHB.38.2.3. PMID: 24629547.

17. Wackowski OA, Delnevo CD. Young adults' risk perceptions of various tobacco products relative to cigarettes - results from the National Young Adult Health Survey. Health Educ Behav. 2016; 43(3): 328336. doi: 10.1177/1090198115599988. PMID: 26304709.

18. Martinasek MP, Bowersock A, Wheldon CW. Patterns, Perception and Behavior of Electronic Nicotine Delivery Systems Use and Multiple Product Use Among Young Adults. Respir Care. 2018;63(7):913919. doi: 10.4187/respcare.06001. PMID: 29588352.

19. Pericot-Valverde I1, Gaalema DE2, Priest JS3, Higgins ST2. E-cigarette awareness, perceived harmfulness, and ever use among U.S. adults. Prev Med. 2017;104:92-99. doi: 10.1016/j.ypmed.2017.07.014. Epub 2017 Jul 17. PMID: 28729198.
20. Agaku I, Odani S, Vardavas C, Neff L. Self-Identified Tobacco Use and Harm Perceptions Among US Youth. Pediatrics. 2018;141(4). Epub 2018 Mar 15. doi: 10.1542/peds.2017-3523. PMID: 29545271.

21. Wagoner KG, Cornacchione J, Wiseman KD, et al. Ecigarettes, Hookah Pens and Vapes: Adolescent and Young Adult Perceptions of Electronic Nicotine Delivery Systems. Nicotine \& Tobacco Research, 2016, 18(10):2006-2012. doi: 10.1093/ntr/ntw095. PMID: 27029821

22. U.S. Food and Drug Administration. FDA finalizes enforcement policy on unauthorized flavored cartridge-based e-cigarettes that appeal to children, including fruit and mint. https://www.fda.gov/newsevents/press-announcements/fda-finalizesenforcement-policy-unauthorized-flavored-cartridgebased-e-cigarettes-appeal-children. Accessed September 8, 2020.

23. Winnicka L, Shenoy MA. EVALI and the Pulmonary Toxicity of Electronic Cigarettes: A Review. J Gen Intern Med. 2020 Apr 3. doi: 10.1007/s11606-02005813-2. [Epub ahead of print]

24. Wang B, King BA, Corey CG, et al. Awareness and Use of Non-conventional Tobacco Products Among U.S. Students, 2012. Am J Prev Med. 2014; 47(2 0 1): S36S52. doi: 10.1016/j.amepre.2014.05.003. PMID: 25044194.

25. Wiseman KD, Cornacchione J, Wagoner KG, et al. Adolescents' and Young Adults' Knowledge and Beliefs About Constituents in Novel Tobacco Products. Nicotine \& Tobacco Research, 2016, 15811587. doi: 10.1093/ntr/ntw009. PMID: 26764259.

26. McBane SE, Corelli RL, Albano CB, et al. The role of academic pharmacy in tobacco cessation and control. Am J Pharm Educ. 2013 Jun 12;77(5):93. doi: 10.5688/ajpe77593.

27. Dent LA, Harris KJ, Noonan CW. Tobacco interventions delivered by pharmacists: a summary and systematic review. Pharmacotherapy. 2007 Jul;27(7):1040-51. doi: 10.1592/phco.27.7.1040.

28. Mclntosh S, Wall AF, Johnson T, et al. Tobacco Control at Community Colleges: Context and Opportunities. Tob Prev Cessat. 2016;2. pii: 76. doi: 10.18332/tpc/66949. Epub 2016 Dec 1. PMID: 29218328.

29. Bennet BL, Deiner M, Pokhrel P. College anti-smoking policies and student smoking behavior: a review of the literature. Tobacco Induced Diseases.

2017;15:11:1-11. doi: 10.1186/s12971-017-0117-z. PMID: 28163669.

30. Braverman MT, Geldhof GJ, Hoogesteger LA, Johnson JA. Predicting students' noncompliance with a smokefree university campus policy. Prev Med.

2018;114:209-216. doi: 10.1016/j.ypmed.2018.07.002. Epub 2018 Jul 3. doi: 10.1016/j.ypmed.2018.07.002. PMID: 30049663. 
Table 1. Participant Demographics

\begin{tabular}{|c|c|c|}
\hline Factor & & $(N=99)^{*}$ \\
\hline \multirow[t]{2}{*}{ Gender } & Female & $64(64.6)$ \\
\hline & Male & $35(35.3)$ \\
\hline \multirow[t]{5}{*}{ Race } & African-American/Black & $66(66.7)$ \\
\hline & Asian or Pacific Islander & $5(5.1)$ \\
\hline & Caucasian & $21(21.2)$ \\
\hline & Hispanic & $3(3.0)$ \\
\hline & Other & $4(4.0)$ \\
\hline \multirow[t]{5}{*}{ Highest education level } & High school graduate & $61(61.6)$ \\
\hline & Associate's degree & $13(13.1)$ \\
\hline & Bachelor's degree & $16(16.2)$ \\
\hline & Master's degree & $7(7.1)$ \\
\hline & Doctorate degree & $2(2.0)$ \\
\hline \multirow[t]{5}{*}{ Academic Major } & Business & $11(11.1)$ \\
\hline & Technology & $45(45.4)$ \\
\hline & Natural sciences & $20(20.2)$ \\
\hline & Liberal arts & $14(14.1)$ \\
\hline & Other & $9(9.1)$ \\
\hline \multirow[t]{2}{*}{ Prior tobacco usage } & No & $47(47.4)$ \\
\hline & Yes & $52(52.5)$ \\
\hline \multirow[t]{5}{*}{ Tobacco product usage } & Chewing tobacco & $3(3.0)$ \\
\hline & Electronic cigarettes & $15(15.1)$ \\
\hline & Hookah & $32(32.3)$ \\
\hline & Cigarettes & $26(26.2)$ \\
\hline & Cigars & $2(2.0)$ \\
\hline \multirow[t]{2}{*}{ Duration of tobacco usage } & Less than 5 years & $45(45.5)$ \\
\hline & Over 5 years & $6(6.1)$ \\
\hline \multirow[t]{4}{*}{ Tobacco usage frequency } & Once a day & $9(9.1)$ \\
\hline & Once a week & $2(3.9)$ \\
\hline & Once a month & $1(2.0)$ \\
\hline & A couple of times a year & $39(39.4)$ \\
\hline \multirow[t]{5}{*}{ Number of quit attempts } & 0 attempt & $37(37.3)$ \\
\hline & 1 attempt & $7(7.1)$ \\
\hline & 2 attempts & $1(1.0)$ \\
\hline & 3 attempts & $1(1.0)$ \\
\hline & 4 or more attempts & $5(5.1)$ \\
\hline
\end{tabular}


Figure 1. Comparison of Least Harm and Most Benefit between Tobacco Products Reported Among College Students*
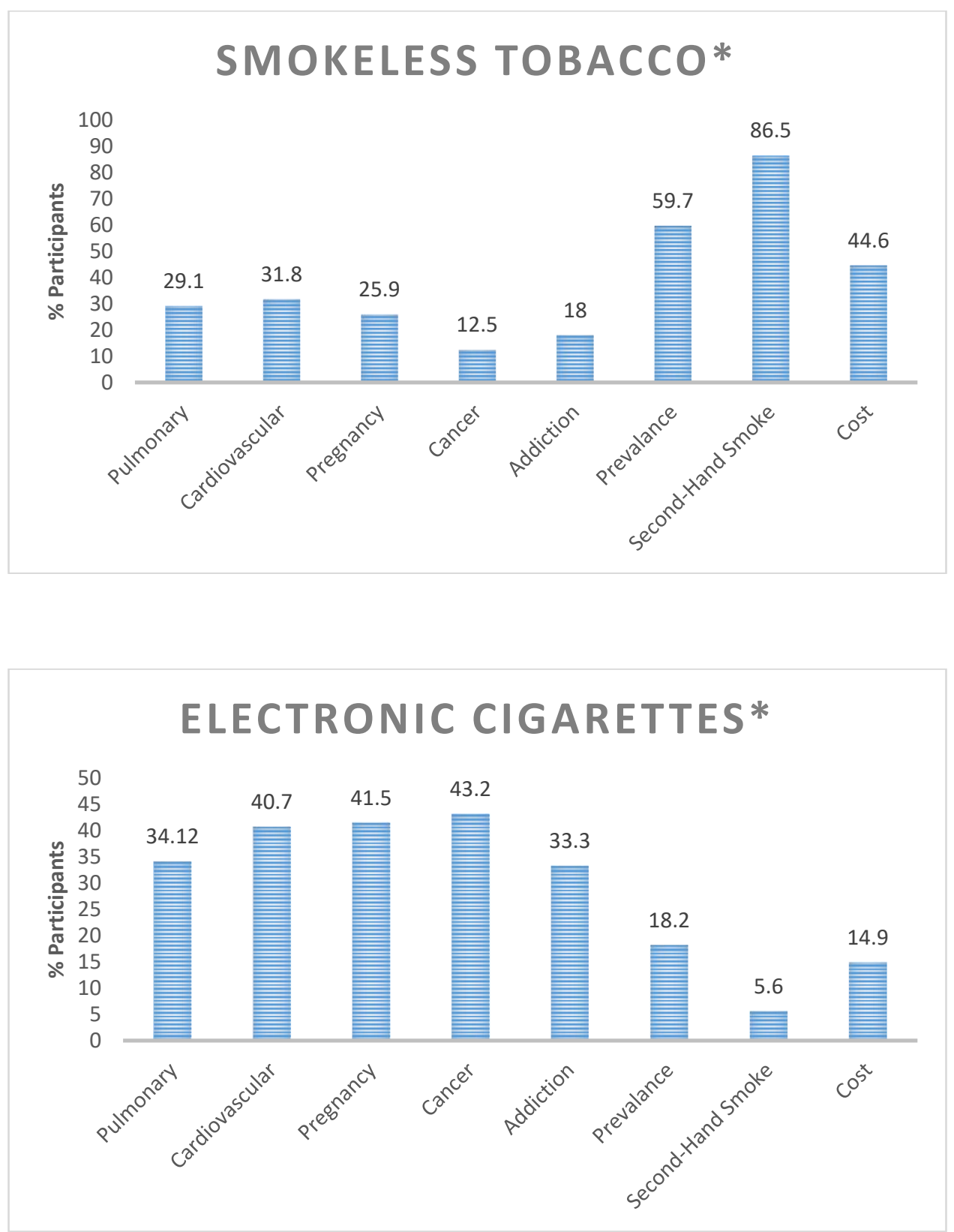

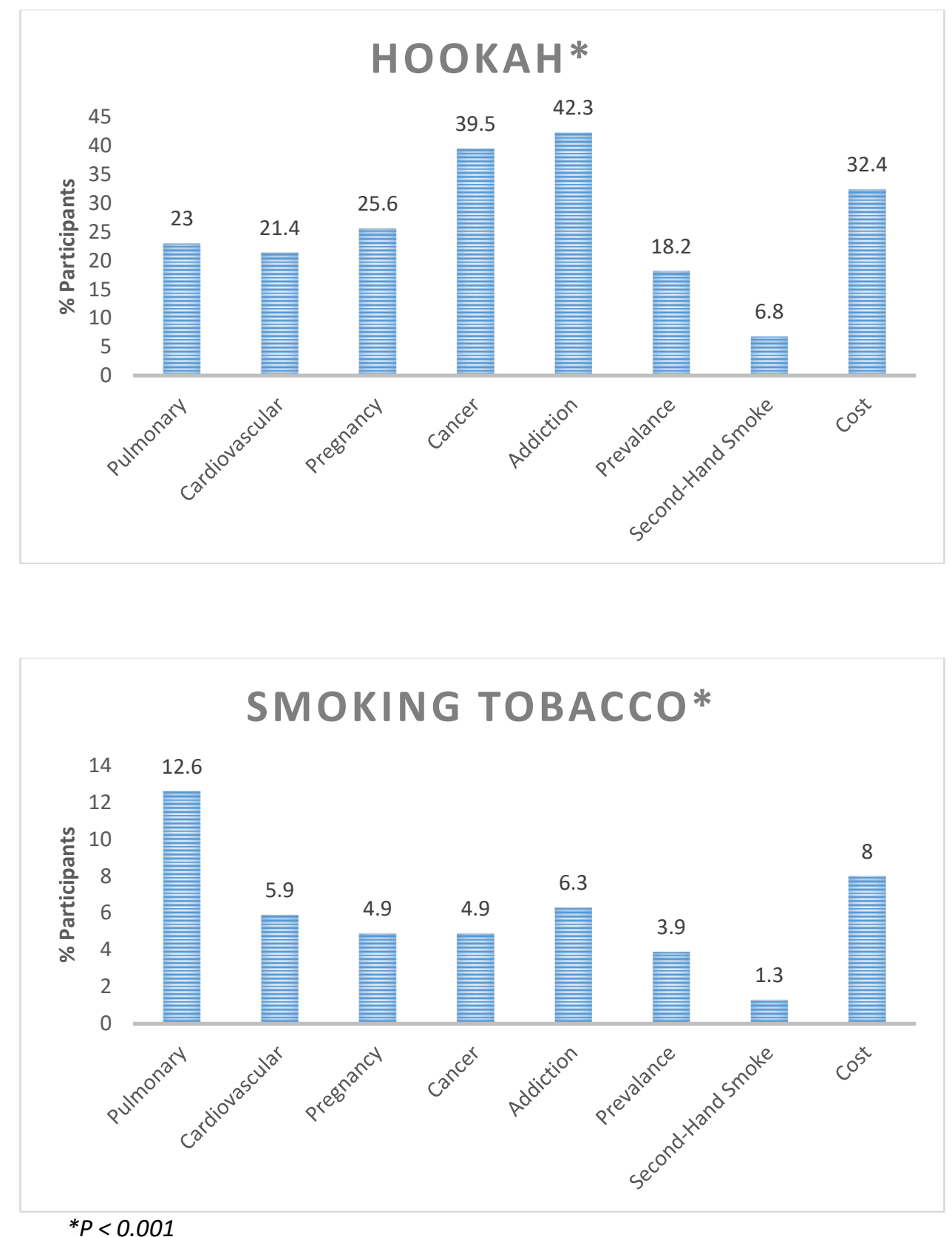
Appendix I: The Health Belief Model as a Predictor of Preventative Health Behavior

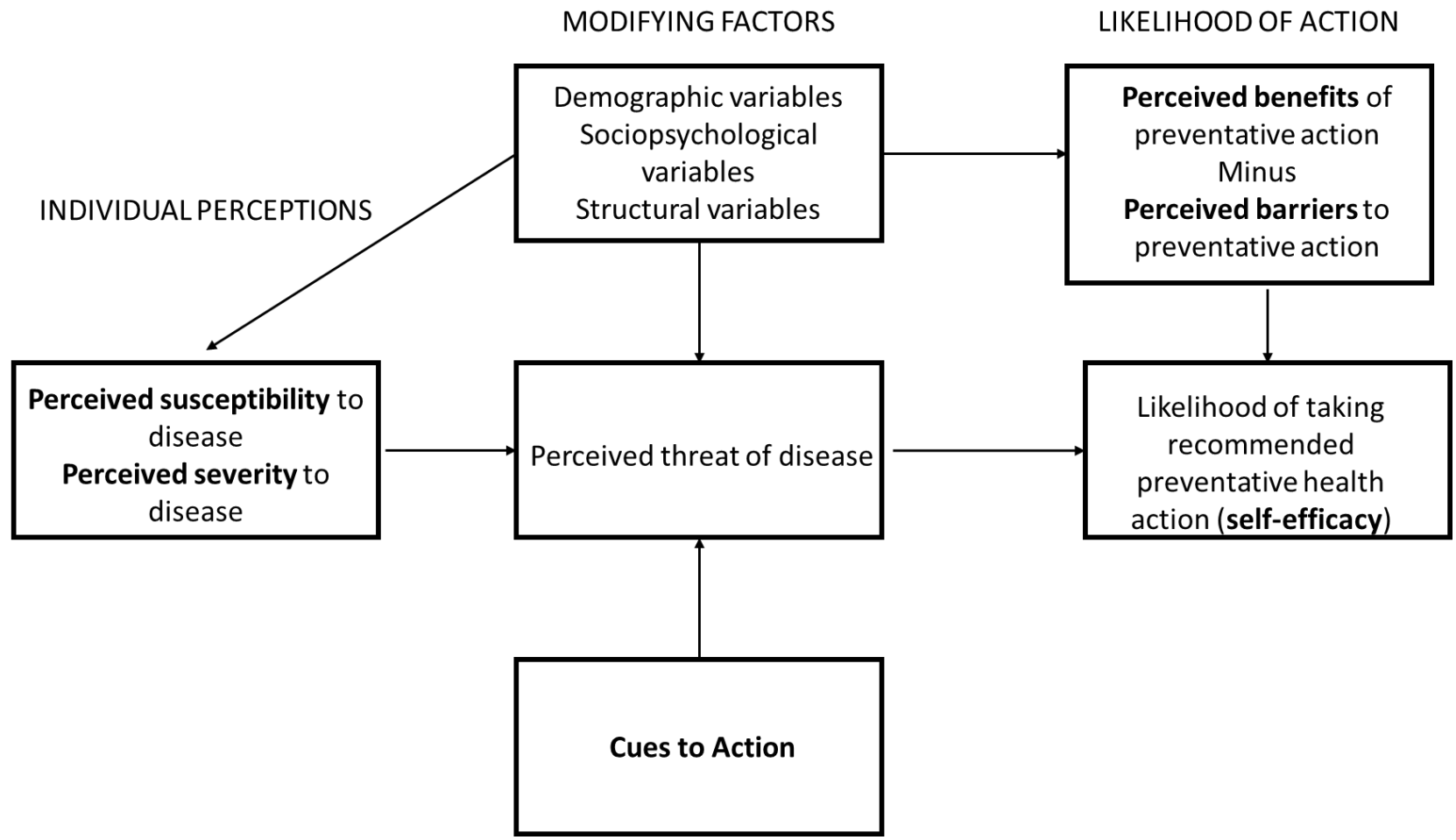

Appendix II: Definitions and Examples of Common Tobacco Products

\begin{tabular}{|l|l|l|}
\hline Tobacco Product & Definition & Examples \\
\hline Cigarettes & $\begin{array}{l}\text { Small rolls of porous paper containing } \\
\text { tobacco }\end{array}$ & Marlboro, Camel, Newport \\
\hline Cigars & Rolled tobacco wrapped in a tobacco leaf & $\begin{array}{l}\text { Macanudo, Romeo y Julieta, Black } \\
\text { \& Mild }\end{array}$ \\
\hline Smokeless tobacco & $\begin{array}{l}\text { Products that are placed in the mouth for } \\
\text { chewing, sucking, or spitting }\end{array}$ & $\begin{array}{l}\text { Redman, Levi Garrett, Beechnut, } \\
\text { Skoal, Grizzly }\end{array}$ \\
\hline E-cigarettes & $\begin{array}{l}\text { Battery-powered devices that produce } \\
\text { vapor instead of smoke }\end{array}$ & Blu, JUUL \\
\hline Hookah & Smoking tobacco in a water pipe & $\begin{array}{l}\text { Starbuzz Carbine, Regal Queen } \\
\text { Redwood, Shika Legend }\end{array}$ \\
\hline
\end{tabular}

\section{Appendix III. Scoring System for Tobacco Attitudes and Perceptions Survey}

On a scale of $1-4$, rank the four products (smoking tobacco, smokeless tobacco, e-cigarettes, and hookah) in relation to each other where:

1 = least harm and most benefit for health

$2=$ more harm and less benefit for health

$3=$ severe harm and limited benefit for health

$4=$ most harm and least benefit for health

Sample: Rank the four tobacco categories in relation to its effects on the cardiovascular system Respondents could give e-cigarettes a 1 ranking if they thought it caused the least harm and most benefit to the cardiovascular system, followed by a 2 for hookah for higher levels of harm and less benefit, a 3 score for smokeless tobacco for more negative health connotations, and a 4 for smoking tobacco as the most harm and least benefit. 